\title{
Feasibility and Safety of Repeated Transarterial Chemoembolization Using Miriplatin-Lipiodol Suspension for Hepatocellular Carcinoma
}

\author{
TOMOHIRO MATSUMOTO ${ }^{*}{ }^{*}$, HITOSHI ICHIKAWA ${ }^{2}$, JIN IMAI $^{2}$, TOSHIHIKO HAYASHI $^{1}$, KOSUKE TOMITA $^{1}$, \\ TAKAHIKO MINE ${ }^{1}$, SEIICHIRO KOJIMA $^{2}$, NORIHITO WATANABE $^{2}$ and TERUMITSU HASEBE ${ }^{1 *}$ \\ Departments of ${ }^{1}$ Radiology and ${ }^{2}$ Gastroenterology, Tokai University Hachioji Hospital, \\ Tokai University School of Medicine, Hachioji, Japan
}

\begin{abstract}
Aim: To retrospectively evaluate the feasibility and safety of repeated transarterial chemoembolization (TACE) three or more times using miriplatin-lipiodol (M$\angle P D)$ suspension (repeated M-LPD TACE) for hepatocellular carcinoma (HCC). Patients and Methods: Sixteen patients who underwent repeated M-LPD TACE were examined. Total dose of miriplatin, lipiodol and porous gelatin sponge particles and adverse events of the first and last M-LPD TACE were evaluated. Results: The mean \pm standard deviation $(S D)$ of the total number of $M-L P D$ TACE per patient was $3.7 \pm 1.1$. The mean $\pm S D$ dose of total miriplatin, lipiodol and porous gelatin sponge particles per patient was $303 \pm 103 \mathrm{mg}, 21 \pm 7.3 \mathrm{ml}$ and $84 \pm 57 \mathrm{mg}$, respectively. There were no significant differences in any adverse events between the first and last M-LPD TACE. Conclusion: Repeated M-LPD TACE for HCC is feasible and safe in selected patients.
\end{abstract}

Hepatocellular carcinoma (HCC) is one of the most common malignant diseases worldwide (1). Transarterial chemoembolization (TACE) is the most frequently used treatment for managing unresectable HCC, with proven improvement in survival of selected patients $(2,3)$. The first platinum-based anticancer agent, cisplatin, has remarkable antitumor effects in TACE (4-7). However, cisplatin is rather hydrophilic and

*These Authors contributed equally to this study.

Correspondence to: Professor Terumitsu Hasebe, MD, Ph.D. (Dr. Eng.), Professor and Chairman, Department of Radiology, Tokai University Hachioji Hospital, Tokai University School of Medicine, 1838 Ishikawa-machi, Hachioji, Tokyo 192-0032, Japan. Tel: +81 426391111, Fax: +81 426391144, e-mail: hasebe@tokai-u.jp

Key Words: Transarterial chemoembolization, hepatocellular carcinoma, miriplatin. barely soluble in lipiodol (Andre Guerbet, Aulnay-sous-Bois, France), which is a carrier of anticancer agents for targeted chemotherapy for HCC, even when prepared as a powder to increase its solubility in lipiodol. Therefore, only a small volume of cisplatin remains in the tumor for a long period, and most of the agent is released briefly into the bloodstream in the systemic circulation and cause systemic side-effects such as nausea/vomiting and renal dysfunction (8). Furthermore, it has also been reported that hypersensitivity reactions as an adverse effect occurred in $8.9 \%$ of patients who underwent three or more TACE sessions using cisplatin-lipiodol suspension (CLPD) (9). Recently, a new platinum-based anticancer agent, miriplatin (Dainippon Sumitomo Pharma Co., Ltd, Osaka, Japan), that is easily suspended in lipiodol, was developed for intra-arterial treatment of HCC in Japan (10). When lipiodol is injected into an artery supplying HCC nodules, it selectively accumulates in the tumor. A miriplatin-lipiodol suspension (MLPD) deposited within HCC nodules will gradually release active platinum compounds into tumor tissues, thereby exerting prolonged antitumor effects; however, it is minimally transferred into the systemic circulation. Based on these pharmacokinetic characteristics, conventional TACE using MLPD, performed using M-LPD followed by porous gelatin sponge particles, and transarterial infusion chemotherapy using M-LPD have recently been reported to be highly effective and safe $(8,11-13)$. Additionally, M-LPD has been safely used as an anticancer drug in balloon-occluded TACE (14), which has the potential to improve cancer nodule control locally, compared with conventional TACE $(15,16)$. However, the feasibility and safety of repeated M-LPD TACE three or more times including conventional and balloon-occluded TACE (repeated M-LPD TACE) has not yet been evaluated because previous reports on M-LPD TACE dealt with single session only.

Therefore, the purpose of this study was to retrospectively evaluate the feasibility and safety of repeated M-LPD TACE for HCC. 


\section{Patients and Methods}

Study design. This retrospective study was conducted with the approval of the Institutional Review Board (16R-263). Informed consent was obtained for every diagnostic and interventional procedure.

Patients. Between January 2013 and December 2016, 61 patients received repeated M-LPD TACE for the treatment of HCC at our Institution. The inclusion criteria for this study were as follows: (a) the first M-LPD TACE for HCC was initial TACE and (b) only miriplatin was used as the anticancer drug in TACE (Figure 1). Finally, 16 out of the 61 patients (26\%) were included in the study. There were 10 males and six females, with a mean age \pm standard deviation $(\mathrm{SD})$ of $73 \pm 7$ years (range $=58-83$ years) $($ Table I).

The diagnosis of HCC was made based on distinctive computed tomography (CT) and magnetic resonance imaging (MRI) findings, in addition to high serum levels of tumor markers $[\alpha$-fetoprotein (AFP) or protein induced by vitamin $\mathrm{K}$ absence or antagonist-II (PIVKA-II)] (Table I).

TACE. All TACE procedures were performed by three interventional radiologists (T. H., T. M. and T.M.) with more than 10 years' experience in hepatic vascular interventions, using the same angiographic flat-panel detector system (Siemens Medical Solutions, Forchheim, Germany). An appropriate microcatheter or microballoon catheter was coaxially inserted through a 4-Fr catheter via the femoral artery and placed into the tumor feeder vessel. After tumor location was confirmed, infusion of M-LPD, which was prepared by dissolving $70 \mathrm{mg}$ of miriplatin in 4 or $5 \mathrm{ml}$ of lipiodol warmed to $40^{\circ} \mathrm{C}$, was initiated, followed by embolization of each hepatic area containing the target tumors with porous gelatin particles (Gelpart; Nippon Kayaku, Tokyo, Japan) 1 or $2 \mathrm{~mm}$ in diameter. When TACE using a microballoon catheter was performed, M-LPD infusion was continued under microballoon occlusion. Details of microballoon catheter characteristics are summarized elsewhere $(14,17)$. The end-point of M-LPD infusion in conventional and balloon-occluded TACE was as follows: the HCC nodule filled with M-LPD or the portal venous branches were beginning to be filled with M-LPD. The dose of miriplatin and lipiodol per session was limited to $140 \mathrm{mg}$ and $10 \mathrm{ml}$ for all patients, respectively.

Parameters investigated. We investigated total dose of M-LPD and porous gelatin sponge particles, and adverse events of the first and last M-LPD TACE, which were graded according to the Common Terminology Criteria for Adverse Events version 4.0 (CTCAE v4.0) (18).

Statistical analysis. For statistical analysis, commercial software (JMP 12; SAS Japan, Tokyo, Japan) was used. Statistical analyses were performed using the Wilcoxon test or Wilcoxon signed-rank test for nonparametric data as appropriate. Differences were considered significant when the $p$-value was 0.05 or in the analyses.

\section{Results}

The total number of M-LPD TACE was 59 sessions. The total number of repeated M-LPD TACE was 27 sessions. The mean \pm SD number of M-LPD TACE per patient was $3.7 \pm 1.1$

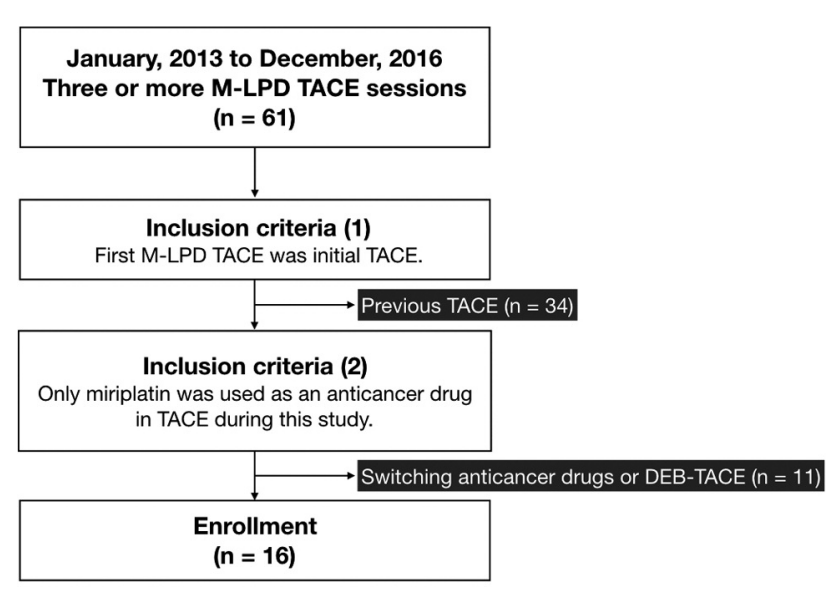

Figure 1. Flowchart for the patients of this study. M-LPD: Miriplatinlipiodol suspension, TACE: Transarterial chemoembolization, DEBTACE: TACE with drug-eluting beads.

Table I. Patient characteristics of this study $(n=16)$.

\begin{tabular}{lc}
\hline Mean age \pm SD (range), years & $73 \pm 7(58-83)$ \\
Gender, $\mathrm{n}$ & 10 \\
$\quad$ Male & 6 \\
Female & \\
Etiology, $\mathrm{n}$ & 8 \\
$\quad$ HCV & 8 \\
Other & $28.25(3.4-55234.7)$ \\
Median AFP (range), ng/ml & $107.5(10-3735)$ \\
Median PIVKA-II (range), mAU/ml & \\
Stage* & 2 \\
I & 12 \\
II & 2 \\
III & 0 \\
IV & \\
\hline
\end{tabular}

SD: Standard deviation, HCV: hepatitis C virus, AFP: $\alpha$-fetoprotein, PIVKA-II: protein induced by vitamin $\mathrm{K}$ absence or antagonists-II. *Staging as proposed by the Liver Cancer Study Group of Japan.

(range=3-7) sessions. M-LPD TACE was performed at intervals of $231 \pm 189$ (42-836) days.

The mean \pm SD dose of miriplatin, lipiodol and porous gelatin sponge particles per patient was $303 \pm 103$ $($ range $=182-492.8) \mathrm{mg}, 21 \pm 7.3($ range $=13-35) \mathrm{ml}$ and $84 \pm 57$ (range $=28-246.4) \mathrm{mg}$, respectively. The mean $\pm \mathrm{SD}$ dose of miriplatin, lipiodol and porous gelatin sponge particles per session was $83 \pm 36($ range $=21-140) \mathrm{mg}, 5.9 \pm 2.6$ (range $=1.5$ 10) $\mathrm{ml}$ and $22 \pm 21$ (range $=4-44$ ) $\mathrm{mg}$, respectively.

There were no significant differences in Child-Pugh score before the procedure and dose of miriplatin, lipiodol and porous gelatin sponge particles between the first and last MLPD TACE groups (Table II). 
Table II. Characteristics of the first and last miriplatin-lipiodol suspension transarterial chemoembolization (M-LPD TACE) (n=16). Data are the mean $\pm S D$ (range)

\begin{tabular}{lccc}
\hline & First M-LPD TACE & Last M-LPD TACE & $p$-Value \\
\hline Child-Pugh score before the procedure & $5.75 \pm 0.8(5-7)$ & $5.75 \pm 1.1(5-8)$ & $1.0000^{*}$ \\
Miriplatin (mg) & $77 \pm 38(33.6-140)$ & $91 \pm 39(28-140)$ & $0.2978^{\#}$ \\
LPD (ml) & $5.2 \pm 2.8(2-10)$ & $6.6 \pm 2.6(2-10)$ & $0.1505^{\#}$ \\
Porous gelatin sponge particle (mg) & $22 \pm 21(4-64)$ & $24 \pm 11(11.2-54.4)$ & $0.122^{\#}$ \\
\hline
\end{tabular}

*Wilcoxon signed-rank, ${ }^{*}$ Wilcoxon test.

Fever, anorexia and elevation of serum aspartate aminotransferase (AST) and alanine aminotransferase (ALT) levels were observed in most patients after the procedure in both the first and last M-LPD TACE groups. Grade 4 AST elevations were seen in one patient $(6 \%)$ in both the first and last M-LPD TACE groups. Grades 1 and 2 serum creatinine elevation in the first M-LPD TACE group were observed in one $(6 \%)$ and two patients (13\%), respectively. Grades 1 and 2 serum creatinine elevation in the last M-LPD TACE group were observed in two (13\%) and one patient $(6 \%)$, respectively. The three patients in whom serum creatinine elevation was observed after the first and last M-LPD TACE were the same (Table III). The patients' creatinine levels before the first and last M-LPD TACE was the upper limit of normal or slightly high (Table III). Elevation of the serum creatinine level up to $2.32 \mathrm{mg} / \mathrm{dl}$ was observed after the last M-LPD TACE in one patient (Table III). However, recovery from the adverse effect took place within one week. No other serious complications such as liver abscess, hypersensitivity reaction to miriplatin or treatment-related deaths were observed in any M-LPD TACE session.

There were no significant differences between the first and last M-LPD TACE groups in terms of any adverse events (Table IV).

\section{Discussion}

According to Fujiyama et al., the pharmacokinetic parameters of miniplatin, namely $C_{\max }$ (maximum drug concentration), $T_{\text {max }}$ (time to maximum drug concentration) and $\mathrm{t}_{1 / 2}$ (half-life) are 5.3-14.2 mg/ml, 7-183 days and 18.4707.2 days, respectively (19), in comparison with those of cisplatin for which $\mathrm{C}_{\max }$ is $2-3 \mu \mathrm{g} / \mathrm{ml}$ and $\mathrm{t}_{1 / 2}$ is 5-7 days (4), are considerably lower; $C_{\max }$ and $T_{\max }$ of miriplatin are each approximately $1 / 100-1 / 500$ than that of cisplatin, but the half-life is much longer. This reflects the sustained release properties of M-LPD. On the other hand, there is a potential risk for an increase in some adverse events such as hematological toxicity, nausea/vomiting, hypersensitivity reactions and renal dysfunction by repeated M-LPD TACE, paralleling increasing residual miriplatin in the body by
Table III. The course of creatinine $(\mathrm{Cr})$ level in patients with $\mathrm{Cr}$ increase.

\begin{tabular}{llllll}
\hline & \multicolumn{4}{c}{ Cr level (mg/dl) } \\
\cline { 2 - 3 } & \multicolumn{2}{c}{ First M-LPD TACE } & & \multicolumn{2}{c}{ Last-M-LPD TACE } \\
\cline { 2 - 3 } \cline { 5 - 6 } Patient no. & Before & After & & Before & After \\
\hline 1 & 1.43 & 1.73 & & 1.48 & 2.32 \\
2 & 1.08 & 1.14 & & 1.09 & 1.13 \\
3 & 1.65 & 1.79 & & 1.92 & 1.59 \\
\hline
\end{tabular}

M-LPD TACE: Miriplatin-lipiodol suspension transarterial chemoembolization.

performing repeated M-LPD TACE. However, there have been no reports on relevant clinical investigations.

In our study, the toxicity profile for repeated M-LPD TACE was mild and acceptable. There were no significant differences in the Child-Pugh score before the procedure and dose of miriplatin, lipiodol and porous gelatin sponge particles between the first and last M-LPD TACE groups. Furthermore, there were no significant differences in any adverse events between the first and last M-LPD TACE groups. These results suggest that residual miriplatin after performing repeated M-LPD TACE had little or no impact on the patients of our study.

Anorexia and fever frequently emerged as adverse effects in both the first and last M-LPD TACE groups. However, these are reactions that usually accompany hepatic intraarterial infusion as a therapeutic modality. Elevations of serum AST and ALT were observed quite frequently in both the first and last M-LPD TACE groups.

Transient elevations of serum transaminase levels are commonly observed following conventional TACE using MLPD (8, 11-13), balloon-occluded TACE using M-LPD (14) and TACE using other anticancer agents (7, 20-22).

Renal dysfunction is a typical problem with C-LPD TACE. However, repeated M-LPD TACE were possible even in cases of slight renal function decline in our study. 
Table IV. Adverse effects after first and last transarterial chemoembolization with miriplatin-lipiodol suspension (M-LPD TACE) ( $n=16)$.

\begin{tabular}{|c|c|c|c|c|c|c|c|c|c|c|c|}
\hline \multirow[b]{3}{*}{ Adverse effect } & \multicolumn{5}{|c|}{ First M-LPD TACE, n (\%) } & \multicolumn{5}{|c|}{ Last M-LPD TACE, n (\%) } & \multirow[t]{3}{*}{$p$-Value* } \\
\hline & \multirow[b]{2}{*}{ Total } & \multicolumn{4}{|c|}{ Grade (CTCAE v4.0) } & \multirow[b]{2}{*}{ Total } & \multicolumn{4}{|c|}{ Grade (CTCAE v4.0) } & \\
\hline & & 1 & 2 & 3 & 4 & & 1 & 2 & 3 & 4 & \\
\hline White blood cell decrease & $5(31 \%)$ & $2(13 \%)$ & $2(13 \%)$ & $1(6 \%)$ & $0(0 \%)$ & $5(31 \%)$ & $1(6 \%)$ & $2(13 \%)$ & $2(13 \%)$ & $0(0 \%)$ & 0.7813 \\
\hline Aspartate aminotransferase increase & $16(100 \%)$ & $6(38 \%)$ & $2(13 \%)$ & $7(44 \%)$ & $1(6 \%)$ & $16(100 \%)$ & $4(25 \%)$ & $4(25 \%)$ & $7(44 \%)$ & $1(6 \%)$ & 0.8066 \\
\hline Alanine aminotransferase increase & $14(88 \%)$ & $5(31 \%)$ & $2(13 \%)$ & $7(44 \%)$ & $0(0 \%)$ & $13(81 \%)$ & $3(19 \%)$ & $3(19 \%)$ & $7(44 \%)$ & $0(0 \%)$ & 0.9805 \\
\hline Total bilirubin increase & $11(69 \%)$ & $7(44 \%)$ & $4(25 \%)$ & $0(0 \%)$ & $0(0 \%)$ & $12(75 \%)$ & $9(56 \%)$ & $2(13 \%)$ & $1(6 \%)$ & $0(0 \%)$ & 1.0000 \\
\hline Creatinine increase & $3(19 \%)$ & $1(6 \%)$ & $2(13 \%)$ & $0(0 \%)$ & $0(0 \%)$ & $3(19 \%)$ & $2(13 \%)$ & $1(6 \%)$ & $0(0 \%)$ & $0(0 \%)$ & 1.0000 \\
\hline Nausea/vomiting & $2(13 \%)$ & $2(13 \%)$ & $0(0 \%)$ & $0(0 \%)$ & $0(0 \%)$ & $2(13 \%)$ & $2(13 \%)$ & $0(0 \%)$ & $0(0 \%)$ & $0(0 \%)$ & 1.0000 \\
\hline Fever & $9(56 \%)$ & $8(50 \%)$ & $1(6 \%)$ & $0(0 \%)$ & $0(0 \%)$ & $11(69 \%)$ & $10(63 \%)$ & $1(6 \%)$ & $0(0 \%)$ & $0(0 \%)$ & 1.0000 \\
\hline Abdominal pain & $6(38 \%)$ & $4(25 \%)$ & $0(0 \%)$ & $2(13 \%)$ & $0(0 \%)$ & $5(31 \%)$ & $3(19 \%)$ & $2(13 \%)$ & $0(0 \%)$ & $0(0 \%)$ & 0.7188 \\
\hline Anorexia & $12(75 \%)$ & $12(75 \%)$ & $0(0 \%)$ & $0(0 \%)$ & $0(0 \%)$ & $14(83 \%)$ & $13(81 \%)$ & $0(0 \%)$ & $1(6 \%)$ & $0(0 \%)$ & 0.5000 \\
\hline
\end{tabular}

CTCAE v4.0: Common Terminology Criteria for Adverse Events version 4.0 (18). *Wilcoxon signed-rank test.

No hypersensitivity reactions as an adverse effect occurred in any M-LPD TACE session. Although the mechanism of cisplatin-induced hypersensitivity remains unknown, hypersensitivity reactions to platinum compounds seem to be generally mediated by type I hypersensitivity, and platinum compounds dependently induce the direct release of histamine as another mechanism of the hypersensitivity (23). In particular, patients who received three or more sessions of C-LPD conventional TACE had a 13-fold increase in the risk of hypersensitivity reactions (9). Indeed, differences between M-LPD and C-LPD TACE in respect of hypersensitivity reactions as adverse effects are unclear. However, repeated M-LPD TACE may be desirable from the viewpoint of minimizing hypersensitivity reactions.

There are some limitations to the present study, the first being its retrospective design. Secondly, this study was limited by its small sample size. Lastly, we did not evaluate the changes in platinum concentration in the plasma. However, to the best of our knowledge, the present study is the first work that shows the feasibility and safety of repeated M-LPD TACE. Therefore, further investigations into the safety and therapeutic efficacy of repeated M-LPD TACE are clearly necessary.

In conclusion, repeated M-LPD TACE for HCC is feasible and safe in selected patients.

\section{Acknowledgements}

We would like to thank Dr. Shinji Takashimizu, Dr. Junko Nagata and Dr. Hiroyuki Ito of the Department of Gastroenterology, Tokai University Hachioji Hospital, for their help in patient management; and Dr. Kazunobu Hashida and Dr. Satoshi Suda of the Department of Radiology, Tokai University Hachioji Hospital, Tokai University School of Medicine, for continuing support and encouragement.

\section{Conflicts of Interest}

On behalf of all Authors, the corresponding Author states that there is no conflict of interest in regard to this study.

\section{Ethical Approval}

All procedures performed in studies involving human participants were in accordance with the ethical standards of the institutional and/or national research committee and with the 1964 Declaration of Helsinki and its later amendments or comparable ethical standards. None of the Authors was involved in any studies with animals in relation to the preparation of this article.

\section{Informed Consent}

Informed consent was obtained from all participants included in the study.

\section{References}

1 Parkin DM, Bray F, Ferlay $\mathrm{J}$ and Pisani P: Global cancer statistics, 2002. CA Cancer J Clin 55: 74-108, 2005.

2 Llovet JM, Real MI, Montana X, Planas R, Coll S, Aponte J, Ayuso C, Sala M, Muchart J, Sola R, Rodes J and Bruix J: Arterial embolisation or chemoembolisation versus symptomatic treatment in patients with unresectable hepatocellular carcinoma: a randomised controlled trial. Lancet 359: 1734-1739, 2002.

3 Lo CM, Ngan H, Tso WK, Liu CL, Lam CM, Poon RT, Fan ST and Wong J: Randomized controlled trial of transarterial lipiodol chemoembolization for unresectable hepatocellular carcinoma. Hepatology 35: 1164-1171, 2002.

4 Shibata J, Fujiyama S, Sato T, Kishimoto S, Fukushima S and Nakano M: Hepatic arterial injection chemotherapy with cisplatin suspended in an oily lymphographic agent for hepatocellular carcinoma. Cancer 64: 1586-1594, 1989.

5 Kamada K, Nakanishi T, Kitamoto M, Aikata H, Kawakami Y, Ito $\mathrm{K}$, Asahara $\mathrm{T}$ and Kajiyama G: Long-term prognosis of 
patients undergoing transcatheter arterial chemoembolization for unresectable hepatocellular carcinoma: comparison of cisplatin lipiodol suspension and doxorubicin hydrochloride emulsion. $\mathrm{J}$ Vasc Interv Radiol 12: 847-854, 2001.

6 Ikeda M, Maeda S, Ashihara H, Nagahama H, Tanaka M and Sasaki Y: Transcatheter arterial infusion chemotherapy with cisplatin-lipiodol suspension in patients with hepatocellular carcinoma. J Gastroenterol 45: 60-67, 2010.

7 Yodono $\mathrm{H}$, Matsuo $\mathrm{K}$ and Shinohara A: A retrospective comparative study of epirubicin-lipiodol emulsion and cisplatinlipiodol suspension for use with transcatheter arterial chemoembolization for treatment of hepatocellular carcinoma. Anticancer Drugs 22: 277-282, 2011.

8 Okusaka T, Okada S, Nakanishi T, Fujiyama S and Kubo Y: Phase II trial of intra-arterial chemotherapy using a novel lipophilic platinum derivative (SM-11355) in patients with hepatocellular carcinoma. Invest New Drugs 22: 169-176, 2004.

9 Kawaoka T, Aikata H, Katamura Y, Takaki S, Waki K, Hiramatsu A, Takahashi S, Hieda M, Kakizawa $\mathrm{H}$ and Chayama K: Hypersensitivity reactions to transcatheter chemoembolization with cisplatin and Lipiodol suspension for unresectable hepatocellular carcinoma. J Vasc Interv Radiol 21: 1219-1225, 2010.

10 Hanada M, Baba A, Tsutsumishita Y, Noguchi T, Yamaoka T, Chiba N and Nishikaku F: Intra-hepatic arterial administration with miriplatin suspended in an oily lymphographic agent inhibits the growth of tumors implanted in rat livers by inducing platinum-DNA adducts to form and massive apoptosis. Cancer Chemother Pharmacol 64: 473-483, 2009.

11 Okabe K, Beppu T, Haraoka K, Oh-Uchida Y, Yamamura S, Tomiyasu S, Yamanaka T, Sano O, Masuda T, Chikamoto A, Fujiyama $\mathrm{S}$ and Baba H: Safety and short-term therapeutic effects of miriplatin-lipiodol suspension in transarterial chemoembolization (TACE) for hepatocellular carcinoma. Anticancer Res 31: 2983-2988, 2011.

12 Okusaka T, Kasugai H, Ishii H, Kudo M, Sata M, Tanaka K, Shioyama Y, Chayama K, Kumada H, Yoshikawa M, Seki T, Saito H, Hayashi N, Shiratori K, Okita K, Sakaida I, Honda M, Kusumoto Y, Tsutsumi T and Sakata K: A randomized phase II trial of intra-arterial chemotherapy using SM-11355 (Miriplatin) for hepatocellular carcinoma. Invest New Drugs 30: 2015-2025, 2012.

13 Seko Y, Ikeda K, Kawamura Y, Fukushima T, Hara T, Sezaki H, Hosaka T, Akuta N, Suzuki F, Kobayashi M, Suzuki Y, Saitoh $\mathrm{S}$, Arase $\mathrm{Y}$ and Kumada H: Antitumor efficacy of transcatheter arterial chemoembolization with warmed miriplatin in hepatocellular carcinoma. Hepatol Res 43: 942-949, 2013.

14 Matsumoto T, Endo J, Hashida K, Ichikawa H, Kojima S, Takashimizu S, Watanabe N, Yamagami $\mathrm{T}$ and Hasebe $\mathrm{T}$ : Balloon-occluded transarterial chemoembolization using a 1.8French tip coaxial microballoon catheter for hepatocellular carcinoma: technical and safety considerations. Minim Invasive Ther Allied Technol 24: 94-100, 2015.
15 Arai H, Abe T, Takayama H, Toyoda M, Ueno T, Kakizaki S and Sato K: Safety and efficacy of balloon-occluded transcatheter arterial chemoembolization using miriplatin for hepatocellular carcinoma. Hepatol Res 45: 663-666, 2015.

16 Ogawa M, Takayasu K, Hirayama M, Miura T, Shiozawa K, Abe M, Matsumoto N, Nakagawara H, Ohshiro S, Yamamoto T, Tanaka N, Moriyama M, Mutou H, Yamamoto Y and Irie T: Efficacy of a microballoon catheter in transarterial chemoembolization of hepatocellular carcinoma using miriplatin, a lipophilic anticancer drug: Short-term results. Hepatol Res 46: E60-69, 2016.

17 Matsumoto T, Endo J, Hashida K, Mizukami H, Nagata J, Ichikawa H, Kojima S, Takashimizu S, Yamagami T, Watanabe $\mathrm{N}$ and Hasebe T: Balloon-occluded arterial stump pressure before balloon-occluded transarterial chemoembolization. Minim Invasive Ther Allied Technol 25: 22-28, 2016.

18 Common Terminology Criteria for Adverse Events version 4.0, NCI, NIH, 2009. https://evs.nci.nih.gov/ftp1/CTCAE/CTCAE _4.03_2010-06-14_QuickReference_5x7.pdf

19 Fujiyama S, Shibata J, Maeda S, Tanaka M, Noumaru S, Sato K and Tomita K: Phase I clinical study of a novel lipophilic platinum complex (SM-11355) in patients with hepatocellular carcinoma refractory to cisplatin/lipiodol. Br J Cancer 89: 16141619, 2003.

20 Ono Y, Yoshimasu T, Ashikaga R, Inoue M, Shindou H, Fuji K, Araki Y and Nishimura Y: Long-term results of lipiodoltranscatheter arterial embolization with cisplatin or doxorubicin for unresectable hepatocellular carcinoma. Am J Clin Oncol 23: $564-568,2000$

21 Ikeda M, Maeda S, Shibata J, Muta R, Ashihara H, Tanaka M, Fujiyama $\mathrm{S}$ and Tomita K: Transcatheter arterial chemotherapy with and without embolization in patients with hepatocellular carcinoma. Oncology 66: 24-31, 2004.

22 Kawamura Y, Ikeda K, Hirakawa M, Hosaka T, Kobayashi M, Saitoh S, Yatsuji H, Sezaki H, Akuta N, Suzuki F, Suzuki Y, Arase Y and Kumada H: Efficacy of platinum analogue for advanced hepatocellular carcinoma unresponsive to transcatheter arterial chemoembolization with epirubicin. Hepatol Res 39: 346-354, 2009.

23 Cromwell O, Pepys J, Parish WE and Hughes EG: Specific IgE antibodies to platinum salts in sensitized workers. Clin Allergy 9: 109-117, 1979.
Received March 27, 2017

Revised April 13, 2017

Accepted April 19, 2017 